Original Article

\title{
RECONSTRUCTION OF CONDYLE FOLLOWING SURGICAL CORRECTION OF TEM POROM ANDIBULAR JOINT ANKYLOSIS: CURRENT CONCEPTS AND CONSIDERATIONS FOR THE FUTURE
}

\author{
Muralee Mohan C. ${ }^{1}$, B. Rajendra Prasad ${ }^{2}$, Smitha Bhat ${ }^{3} \&$ Shyam S. Bhat ${ }^{4}$ \\ ${ }^{1}$ Professor, ${ }^{2}$ Principal and Dean, ${ }^{3}$ Senior Lecturer, Department of Oral and M axillofacial Surgery, \\ A.B. Shetty M emorial Institute of Dental Sciences, Nitte University, Deralakatte, M angalore - 575018 , \\ ${ }^{4}$ Senior Lecturer, Department Of Oral and M axillofacial Surgery, CIDS, Virajpet, Karnataka, India

Correspondence:
Muralee Mohan C.
Professor, Department Of Oral and M axillofacial Surgery, A.B. Shetty Memorial Institute of Dental Sciences,
Nitte University, Deralakatte, Mangalore - 575018, Karnataka, India.
E-mail: drmuraleemohan@gmail.com

\begin{abstract}
:
Temporomandibular joint (TMJ) ankylosis is one of the most disruptive maladies that can afflict the masticatory system. It is characterized by difficulty or inability to open the mouth due to fusion of the temporal bone and the condyle of the mandible, resulting in facial symmetry/ deformity, malocclusion and dental problems. The only treatment option for TM J ankylosis is surgical with or without condylar reconstruction. Various autogenous grafts are available for condylar reconstruction after freeing the ankylotic mass such as costochondral, fibular, and coronoid. Alloplastic temporomandibular joint (TMJ) prostheses can provide accurate adaptation to the anatomical structures of each individual patient and are a reliable alternative in the treatment of ankylosis. Proving to be a promising method distraction osteogenesis is slowly gaining popularity and may ultimately become the standard procedure, providing a costeffective approach with low morbidity and excellent functional outcomes. Tissue engineering is another budding field which has shown promising results in animal studies but has not been applied to humans.
\end{abstract}

Keywords: Temporomandibular joint, Ankylosis, Distraction Osteogenesis

\section{Introduction :}

Temporomandibular joint (TMJ) ankylosis is a bony or fibrous adhesion of the anatomical joint components by an ankylotic mass. The inability to move the mandible has significant functional and esthetic ramifications, such as the inability to eat and asymmetry of the face. It is primarily caused by trauma, infection, or failed surgery. The treatment of TMJ ankylosis is surgical, either gap arthroplasty, interpositional arthroplasty, and/or joint reconstruction using autogenous grafts or alloplastic

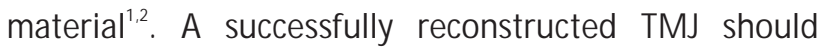
reproduce normal joint structure, provide functional

\begin{tabular}{|c|}
\hline Access this article online \\
\hline Quick Response Code \\
\hline
\end{tabular}

articulation, and permit adaptive growth or remodeling. Difficulty in achieving these treatment goals is illustrated by the multiplicity of autogenous and alloplastic materials proposed or currently used to reconstruct the TMJ. This review discusses the various modes of autogenous and alloplastic condylar reconstruction used in the past, common grafts currently being used and indications of what lies ahead in the field of reconstruction of the condyle.

\section{Costochondral graft}

Most widely accepted autogenous condylar reconstruction involves the use of the costochondral graft (CCG) first described by Sir Harold Gillies in the 1920s. The current technique for TMJ replacement with the CCG was popularized by Poswillo. The sixth or seventh rib is resected along with $1 \mathrm{~cm}$ of intact costal cartilage for CCG. Recently authors have recommended using thinner sections of cartilage $(2-3 \mathrm{~mm})$ due to the potential for overgrowth. CCG is biologically compatible like any autogenous graft, easily workable especially when contouring the cartilaginous part to fit into the glenoid fossa, and takes less time to heal and becomes incorporated into the new environment allowing 
restoration of the bone and cartilage components (Figure 1). CCG also has the capacity for remoulding into an adaptive mandibular condyle, and there is always a potential at the donor site to grow and regenerate. An additional advantage in children is its growth potential. One of the main disputes is the lack of predictable growth ${ }^{4}$. Reankylosis in the range 5-39\% has been reported. Other disadvantages of the CCG are the poor quality of medullary and cortical bone, the possibility of resorption or infection, bone flexibility, elasticity that may cause the graft to be deformed and to produce occlusal changes with time, and the possible separation of the cartilage from the bone. Donor-site complications such as pleural tear, pneumothorax, pleural effusion and atelectasis; empyema; pneumonia and occasional fractures have also been reported ${ }^{5}$.

\section{Iliac crest}

An iliac graft is a chondro-osseous graft, and the graft consists of a full-thickness piece of the iliac crest, including the overlying cartilage layer as a cap. One major advantage especially in growing patients is that the vertical growth pattern of the ilium is converted in the graft to a multidirectional pattern, to be adaptive to the functional demands of the TMJ, restoring the normal growth of the condyle. Harvest of the iliac crest can cause prolonged postoperative pain, altered gait, sensory nerve damage, poor scar/bone contour, delayed healing, herniation of abdominal contents, ilium fracture, peritonitis, and retroperitoneal hematoma ${ }^{6}$.

\section{Fibular}

The fibula is tubular in shape and is densely cortical. It can be easily adapted to passively fit in the glenoid fossa, and its narrow shape allows an easy fit. The main disadvantage of this graft is that it lacks articular cartilage. Donor-site morbidity resulting from fibula flap harvest appears to be more pronounced in the paediatric population than in adults leading to complications, such as great toe flexion contractures and valgus deformity with a tibiotalar tilt. Other notable complications are: ankle stiffness, instability and weakness; numbness of the lateral side of the leg; pedal ischaemia and foot oedema; and partial dehiscence of the fibular donor site?.

\section{Sternoclavicular}

The Sternoclavicular joint (SC) and TMJ are similar anatomically and physiologically. The head of the clavicle contains layers of cartilage that are similar to the mandibular condyle 8 . The SCJ articulation has a growth centre and an interarticular fibrocartilage articular disc that simulates the meniscus of the TM J. When a whole joint is used, the two adjacent synovial compartments and the strong fibrous capsule resemble those in the TMJ. Its absence is also of no great anatomical, functional, or aesthetic consequence. Complete regeneration of the clavicle at the donor site has also been reported, significantly reducing patient morbidity postoperatively.

\section{Metatarsal}

The metatarsophalangeal (MTP) joint can provide a good supply of articular cartilage combined with up to $7 \mathrm{~cm}$ of vascularized bone. The risk of degeneration and reankylosis of the graft is low, especially when used as a vascularized graft. The M TP joint is smaller than the TMJ, so it easily fits within the confines of glenoid fossa. The intact epiphysis in the transplanted M TP joint, which contains an epiphyseal growth plate, ensures the normal growth of the transplant in young patients. There is an acceptable cosmetic result at the donor site, which can be well hidden. A slight foot splaying has been reported, but the main donor-site morbidity is the aesthetic loss of a toe. The M TP joint is a simple hinge joint that does not follow the same movements as the TMJ, and therefore lateral excursion is restricted.

\section{Coronoid}

In 1989, Hong et al. reported the use of coronoid process for condylar reconstruction. The coronoid process shows less bony resorption due to its membranous origin; and especially if the autogenous coronoid process is pedicled on temporal muscle grafts, it shows lesser bony resorption, lesser decrease of height of the mandible ramus and mouth-opening deviation, and better long-term clinical results. Owing to its corticocancellous nature, it is much 
stiffer than CCG, so it can resist heavier forces, and facilitates the use of rigid internal fixation ${ }^{10}$. The main limitation is that if the ankylosed segment also involves the coronoid process it cannot be used as a substitute for condylar reconstruction.

\section{Posterior border of ramus}

In 1986, Loftus et al. reconstructed the condyle by superior repositioning of the pedicled stump of the proximal condylar segment into the condylar fossa as a local osseous pedicled graft based on the lateral pterygoid muscle in a case of osteochondroma ${ }^{11}$. This procedure has recently been extended to cases with ankylosis. This technique avoids the risk of a free graft such as resorption, infection and graft loss and donor-site complications. It provides bone of a size and shape that is adequate for the new condyle and its histological characteristics are similar. The stump of the posterior border of the mandible, placed into the glenoid cavity with reinsertion of the lateral pterygoid muscle, not only results in complete anatomical remodelling, but also leads to good and stable function subsequently.

\section{Alloplastic Devices For Tmj Reconstruction Kent-Vitek Total Prosthesis}

In the early 1970s Kent and colleagues developed a glenoid fossa implant (VK-1) that originally consisted of a bilaminate fossa with a polyaramid fabric reinforced ultrahigh-molecular-weight, polyethylene articular surface ${ }^{12}$. The inner layer of the prosthesis was composed of Proplast-hydroxyapatite, which could be contoured to fit against the base of the skull. This Proplast layer originally came in thicknesses of 2.5 and $4.5 \mathrm{~mm}$. The flange of the prosthesis was secured to the zygomatic arch with screws. The condylar prosthesis was constructed of chromiumcobalt with a layer of Proplast on the inner surface of the ramal flange to encourage rapid ingrowth of both hard and soft tissues. Also, an L-shaped flange was incorporated into the posterior and inferior edge of the ramal surface as an antirotational groove. The original VK-1 fossa had an articulating surface composed of poly tetrafluoroethylene (PTFE). The fossa was revised and called the VK-2 fossa, and its articulating surface was composed of ultra-highmolecular-weight polyethylene (UHM-WPE). Complications included glenoid fossa resorption, especially in patients who had undergone ramal lengthening ${ }^{13}$.

\section{Christensen Prosthesis}

The Christensen TMJ fossa eminence prosthesis (FEP) is designed to be used alone as a partial joint for treatment of severe internal derangement, adhesions, disc perforation, and ankylosis. The condylar prosthesis is always used in conjunction with a FEP and constitutes a total joint replacement (TJR) (Figure2). Christensen was the first person to attempt to cover the fossa eminence with an anatomically correct device to treat ankylosis ${ }^{14}$. Christensen reported on total joint replacement with the fossa eminence devices in conjunction with cobalt-chrome (Co-Cr) alloy condylar prosthesis, which had a molded polymethylmethacrylate (PM MA) head ${ }^{15}$.

\section{Lorenz Prosthesis}

The basic goal for the Lorenz total joint prosthesis was to maximize the mating of articular surfaces, which was accomplished with a spherical condylar head. This design feature allows positional freedom of the mandibular component, following fixation of the fossa component, in all planes without sacrificing the desired articulation ${ }^{16}$. The mandibular component is manufactured from cobaltchrome ( $\mathrm{Co}-\mathrm{Cr}$ ) alloy with a roughened titanium plasma coating on the host bone side of the ramal plate. The condylar component is secured to the ramus with selfretaining, cross drive $2.7-\mathrm{mm}$ self-tapping bone screws made of titanium alloy (TI-6AL-4V). The ramus of the mandibular component is currently manufactured in lengths of $45 \mathrm{~mm}, 50 \mathrm{~mm}$, and $55 \mathrm{~mm}$. The fossa component is manufactured from a specific grade of ultrahigh molecular weight polyethylene (UHM WPE) called ArCom manufactured by Biomet (Warsaw, IN) specifically for use in articulating orthopedic joint designs (Figure3). The fossa is fixed to the zygomatic arch with self-retaining, selftapping 2-mm cross drive screws. These screws are also manufactured from TI-6AL-4V titanium alloy. 


\section{TMJ Concepts/ Techmedica Custom Made Total Joint Prosthesis}

Total alloplastic joint reconstruction is a biomechanical rather than a biologic solution for the treatment of severe joint disease. It provides an efficient and effective means of dealing with distorted articular anatomy, while avoiding the issue of the vascularity of the periarticular tissues so essential in autogenous reconstruction, and it eliminates the need for a second surgical site with all the morbidity involved ${ }^{17}$. However, there is a need for a custom total alloplastic temporomandibular joint (TMJ) reconstruction prosthesis because of the increasing number of functionless, multiply operated TMJs in which a stock prosthesis is unable to correct the mutilated or variable anatomy(Figure4). These prostheses were CAD/CAM devices (computer assisted design/computer assisted manufacture), designed to fit the specific anatomical requirementsfor each patient ${ }^{18}$.

\section{Distraction Osteogenesis/ Transport Distraction}

In 1997, Stucki-M ccormick was the first to apply transport distraction osteogenesis (DO) for TMJ reconstruction in two cases of tumour involving the condyle. The technique involves creating a transport disc of bone from the ramus of the mandible with an L-shaped osteotomy whilst preserving the medial periosteum and muscle attachments to ensure an intact blood supply. The transport disc, after a latency period of 7 days, is advanced $1.0 \mathrm{~mm} /$ day $(0.5 \mathrm{~mm}$ twice daily) until contact is made with the glenoid fossa and proper ramus height is established. The distraction device is then held in place for 5 weeks until there is radiographic evidence of mineralisation at the trailing edge of the transport disc resulting in bridging of the defect without the need for bone grafting. The leading edge of the transport disc tends to remodel and become rounded to form a neocondyle(Figure5). The authors further observed, in the post-distraction MRI scans, an intervening fibrous tissue layer which apparently performed as a pseudo disc. Gap arthroplasty and bidirectional transport distraction of the mandibular ramus is a good and effective therapeutic option in the treatment of ankylosis and especially unilateral TMJ ankylosis associated with facial asymmetry $^{19}$. The mandibular lengthening obtained by gradual distraction can result not only in expansion of the mandibular bony tissue but in proportional and harmonic modification of the muscles and the surrounding soft tissues. The forces produced by the distractor on the mandible are similar to physiological forces during mandibular development. Distraction seems to have beneficial effects, therefore, not only on the harmony of the craniofacial complex but also on temporomandibular articulation. By reestablishing correct function of the soft and skeletal tissues, it is possible to regain the normal potential growth of the mandible ${ }^{20}$. DO is a lengthy procedure requiring close monitoring of the patient. The long course of treatment required for distraction and consolidation may result in pintract soft-tissue infection, bone infection, and psychological problems, and is the major disadvantage of thistechnique ${ }^{21}$.

\section{Tissue Engineering And Role Of Stem Cells}

The principal elements of tissue engineering are the creation of a scaffold into which cells are seeded, and an applied biochemical or biomechanical stimulus to make the cells grow and secrete substances that eventually produce the desired tissue that can be used to replace diseased or missing tissue in humans. Ideally, an osteochondral construct in the shape of the mandibular condyle would be seeded with chondrocytes or chondrogenic cells, and osteoblasts or osteogenic cells to create a functional substitute of the mandibular condyle ${ }^{22}$. Bone, connective tissue, and muscle are potentially repairable through the use of mesenchymal stem cells. Pluripotential stem cells have the inherent ability to be transformed into many different types of tissue, depending on the growth environment to which they are subjected. Presumably, the differentiation of stem cells into the phenotype(s) of the injured tissues is due to the presence of soluble factors (e.g., growth factors, chemokines, etc) that are released from the injured tissues. Mesenchymal stem cells can be harvested from bone marrow as well as from fat via liposuction. The latter represents an easily obtainable source of autologous stem cells for therapeutic needs ${ }^{23}$ 
Table 1. : Autogenous grafts for condylar reconstruction: advantages and limitations

\begin{tabular}{|c|c|c|}
\hline & Advantages & Limitations \\
\hline $\begin{array}{l}\text { I.Graft derived from the distant site } \\
\text { Costochondral }\end{array}$ & $\begin{array}{l}\text { Most widely used, Has a cartilage cap, } \\
\text { mimicking both the bone and cartilaginous } \\
\text { components, Has intrinsic growth potential } \\
\text { Easy accessibility and adaptation, Gross } \\
\text { anatomical similarity to the mandibular } \\
\text { condyle }\end{array}$ & $\begin{array}{l}\text { Unpredictable growth, Poor bone quality } \\
\text { Possible separation of cartilage from bone } \\
\text { Possible donor-site complications: pleural } \\
\text { tear, pneumothorax, pleural effusion, } \\
\text { atelectasis, empyema }\end{array}$ \\
\hline Sternoclavicular & $\begin{array}{l}\text { Similar anatomical and physiological } \\
\text { characteristics, Consists of acartilaginouscap, } \\
\text { Option for a whole joint graft, Has the } \\
\text { potential for growth, Probability of } \\
\text { regenerationat donorsite }\end{array}$ & $\begin{array}{l}\text { Unacceptable location of surgical scar Donor- } \\
\text { site complications: damage to the great } \\
\text { vessels, instability of the clavicle under stress } \\
\text { with resulting shoulder instability, Clavicle } \\
\text { fracture }\end{array}$ \\
\hline Fibular & $\begin{array}{l}\text { Tubular in shape and densely cortical } \\
\text { Vascularized graft has better survival rate } \\
\text { Moresuitable for large mandibular defects }\end{array}$ & $\begin{array}{l}\text { Lacks articular cartilage, Donor-site } \\
\text { complications: great toe flexion contractures } \\
\text { and valgus deformity, ankle stiffness, } \\
\text { instability and weakness; numbness of the } \\
\text { lateral side of the leg; pedal ischaemia and } \\
\text { footoedema }\end{array}$ \\
\hline Iliac crest & $\begin{array}{l}\text { Has a cartilage cap, mimicking both the bone } \\
\text { and cartilaginous components Has potential } \\
\text { for growth M ore suitable for large mandibular } \\
\text { defects }\end{array}$ & $\begin{array}{l}\text { Donor-site complications: altered gait, poor } \\
\text { scar/bone contour, herniation of abdominal } \\
\text { contents, ilium fracture, peritonitis, and } \\
\text { retroperitoneal haematoma }\end{array}$ \\
\hline M etatarsophalangeal & $\begin{array}{l}\text { Combination of articular cartilage and bone } \\
\text { Fitting anatomy because of small size Has } \\
\text { potential for growth }\end{array}$ & $\begin{array}{l}\text { Donor-site complications: aesthetic loss of a } \\
\text { toe M TP joint being a simple hinge joint does } \\
\text { not follow the same movements as the TMJ II. } \\
\text { Grafts derived from the vicinity }\end{array}$ \\
\hline Coronoid & $\begin{array}{l}\text { Avoidance of a secondary surgical site and } \\
\text { associated donor complications, Long- } \\
\text { standing cases usually have elongated and } \\
\text { sturdycoronoid }\end{array}$ & $\begin{array}{l}\text { Ankylosed segment also involves the coronoid } \\
\text { process, then not possible to use, Relatively } \\
\text { pointed architecture, No long-term studies }\end{array}$ \\
\hline Posterior border of ramus & $\begin{array}{l}\text { Bone of a size and shape adequate for new } \\
\text { condyle with similar histological } \\
\text { characteristics, Isapedicled graft }\end{array}$ & $\begin{array}{l}\text { Damage to the contour of the mandibular } \\
\text { angle Lack of growth, Two extra-oral incisions } \\
\text { which might be unappealing for aesthetically } \\
\text { concerned patients, Lack of long-term studies }\end{array}$ \\
\hline Ankyloticmass & $\begin{array}{l}\text { Dense bone with a smooth cortical surface } \\
\text { Recycling of bonyankylotic mass }\end{array}$ & $\begin{array}{l}\text { Bulk resection is a must, Possibility of risking } \\
\text { the nearby structures especially the internal } \\
\text { maxillary artery and facial nerve. Lack of } \\
\text { literature regarding long-term efficacy }\end{array}$ \\
\hline III. Transport distraction & $\begin{array}{l}\text { No need for interpositional material Patients } \\
\text { can open and close their mouths and } \\
\text { masticate during DO, Simultaneous } \\
\text { correction of secondary deformities } \\
\text { Considerable shortens the admission and } \\
\text { operation time, the risk of surgery, and the } \\
\text { possibility of relapse }\end{array}$ & $\begin{array}{l}\text { Lengthy procedure Patient cooperation is a } \\
\text { must }\end{array}$ \\
\hline IV. Tissue engineering & $\begin{array}{l}\text { Avoidance of morbidity associated with } \\
\text { second surgical site }\end{array}$ & $\begin{array}{l}\text { Regeneration of a single tissue, but involves } \\
\text { two integrated tissues, Still in infancy }\end{array}$ \\
\hline
\end{tabular}



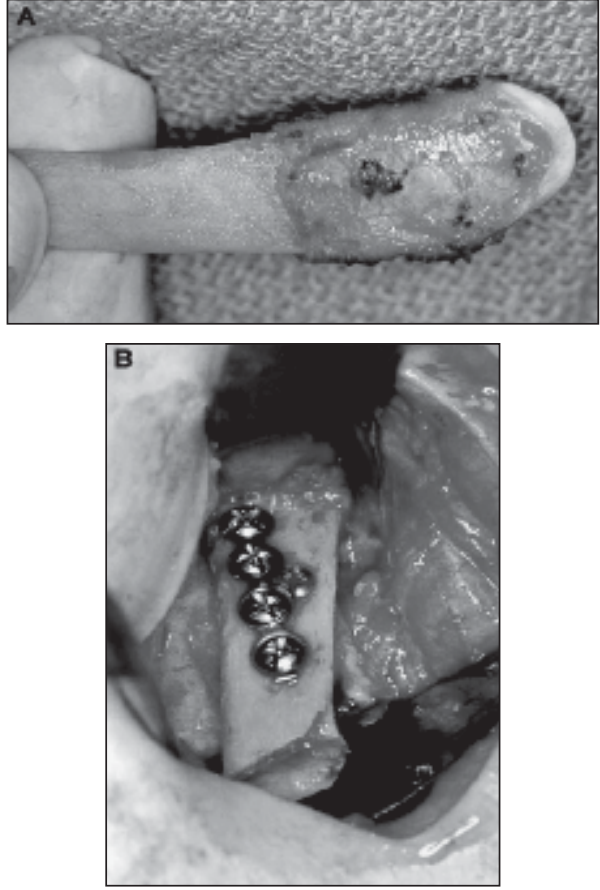

Figure1. (A) Contoured rib before insertion.

(B) Rib fixated in situ to lateral ramus with miniplate and position screw.
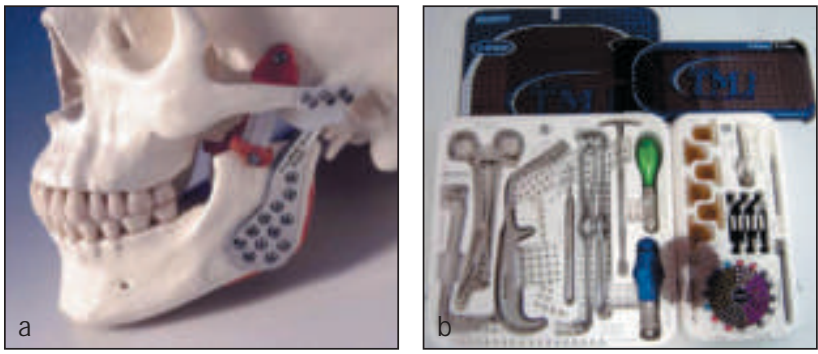

Figure 3. Lorenz Prosthesis

A

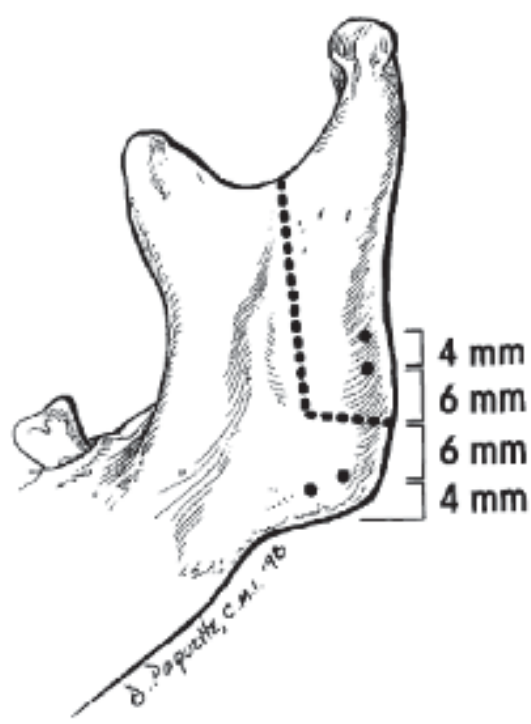

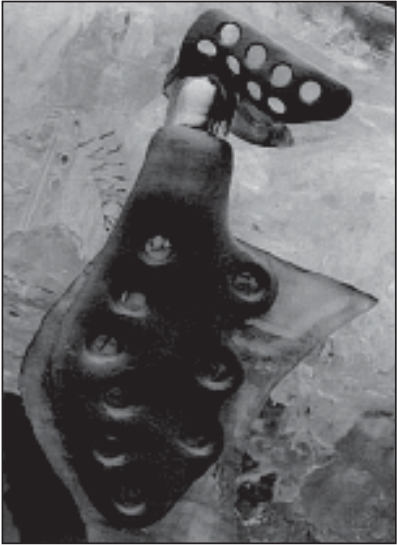

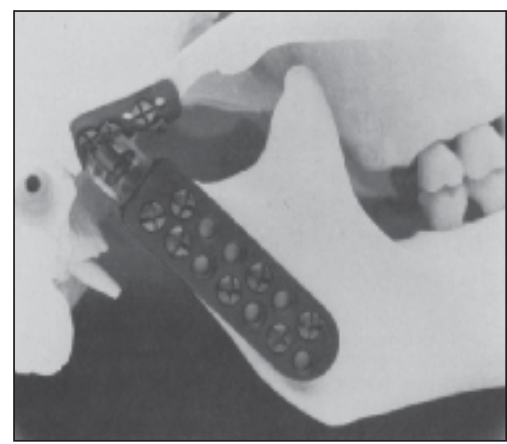

Figure 2. (A), (B) Patient-Specific all metal TJR mounted on a stereolithography model of the patient for which the prosthesis wasfabricated.
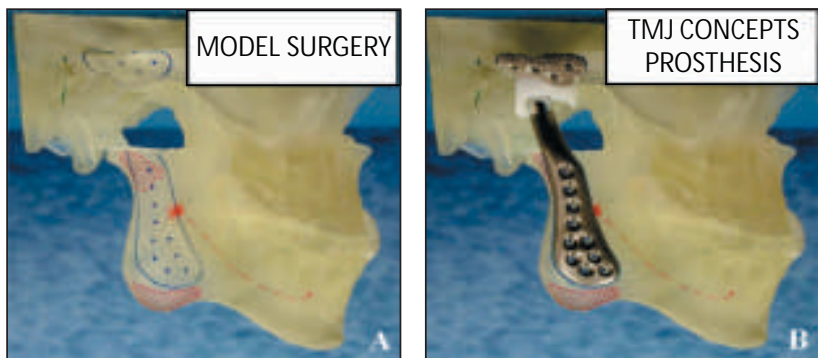

Figure 4. The TMJ Concepts/Techmedica TMJ prosthesis

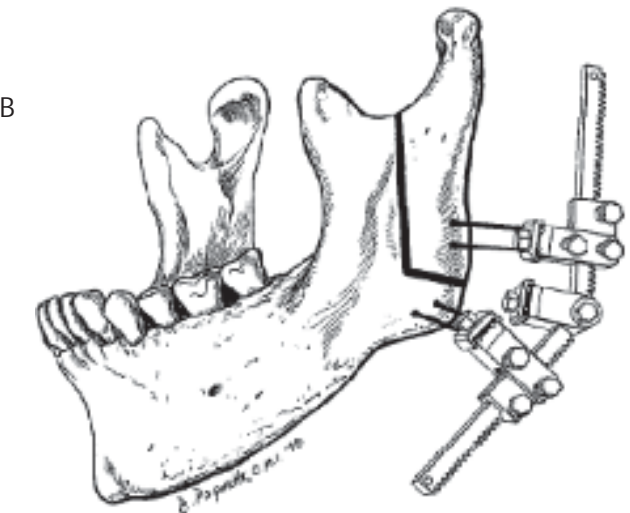

Figure5. (A) A reverse $L$ corticotomy is made in the lateral cortex with the vertical aspect extending from the sigmoid notch to approximately $10 \mathrm{~mm}$ from the angle. The horizontal corticotomy extends to the posterior border of the mandible. (B) the distractor appliance is secured on the pins in a predetermined angle, tightened and secured. 


\section{Discussion :}

The TMJ is a multiaxial, ginglymoarthroidal synovial joint endowed with a capacity to perform a wide range of movements, primarily through its bicondylar mandible freely articulating with a stationary (fixed) fossa of the squamous temporal bone ${ }^{24}$.

The challenge of TMJ ankylosis is an age old problem, and despite advances in surgical treatment the basic problems facing the clinician remain the same: restoration of mandibular function, prevention of recurrent ankylosis and provision for potential jaw growth in paediatric patients. The three principal surgical methods include the simple gap arthroplasty, interpositional

arthroplasty and total joint replacement with a prosthesis. The choice of procedure will be influenced by the patient's preferences and the surgeon's training and experience.

Clinically in mandibular reconstruction, where a condyle is absent, the jaw deviates laterally more when opening the mouth than in those with a condyle. When closing the mouth, tangential rather than vertical striking occurs on the occlusal surfaces, making mastication more difficult. The main contribution of condylar reconstruction is to decrease lateral deviation and improve stability. Autogenous grafts have been tested over time and are the most commonly used grafts for condylar reconstruction. The most significant attribute of autogenous tissues is that they are not intrinsically harmful. They enjoy almost universal host acceptance with low rates of rejection, resorption and infection, and are easily workable at the operating table. Either hard or soft, they are adaptable to their host sites, and once in place generally adapt and remodel appropriately to the stresses put upon them. Their harvest entails discomfort at the donor sites, but seldom

\section{References:}

1. Vasconcelos BC, Bessa-Nogueira RV, Cypriano RV. Treatment of temporomandibular joint ankylosis by gap arthroplasty. Med Oral Patol Oral Cir Bucal 2006; 11: E66-9.

2. Vasconcelos BC, Porto GG, Bessa- Nogueira RV, Nascimento MM. Surgical treatment of temporomandibular joint ankylosis: follow-up of 15 cases and literature review. Med Oral Patol Oral Cir Bucal 2009; 14: E34-8.

3. Poswillo DE. Biological reconstruction of the mandibular condyle. $\mathrm{Br}$ J Oral M axillofac Surg 1987;25:100-4.

4. El-Sayed KM. Temporomandibular joint reconstruction with leaves patients significantly compromised. Table 1 provides a summary of the available grafts and methods for condylar reconstruction (Table 1 ) $^{19}$. Total alloplastic TM J reconstruction prostheses definitely have a place in the armamentarium of the experienced TMJ surgeon. They have been in the past, and will continue to be in the future important modalities in the management of the severely degenerated, anatomically mutilated, functionless TMJs. The increase in the quality of life these patients gain post implantation is akin to that found in the orthopedic population with peripheral joint implants. With continued research and development, these devices will become more functionally stable, providing patients with longterm success. Recently distraction osteogenesis has been used for condylar reconstruction. The chance of reankylosis is negligible, so this method may prove to be the treatment of choice in the coming years. Tissue engineering and the burgeoning field of biomimetics, replacement of tissues and organs with biologically engineered tissues, organs and other body parts including joints, certainly have the potential for altering the way surgeons will deal with joint reconstruction in the future. Although there is definitely a future for engineered grafts, their routine clinical application is a long way off.

\section{Conclusion :}

TMJ reconstruction has been one of the greatest challenges to surgeons over decades, the reason being that TMJ ia a complex anatomic structure. Postoperative defects of TMJ can lead to poorer esthetic and functional outcomes. With improved knowledge on distraction osteogenesis and new avenues of tissue engineering the day is not too far when the surgeon will be able to provide a better quality of life with optimum function and esthetics to a patient operated for TMJ ankylosis.

costochondral graft using modified approach. Int $\mathrm{O}$ Oral M axillofac Surg 2008;37:897-902.

5. Baek RM, Song YT. Overgrowth of a costochondral graft in reconstruction of the temporomandibular joint. Scand J Plast Reconstr Surg Hand Surg 2006;40:179-85.

6. Laurie SW, Kaban LB, Mulliken JB, Murray JE. Donor-site morbidity after harvesting rib and iliac bone. Plast Reconstr Surg 1984;73:933-8.

7. Sieg P, Zieron JO, Bierwolf S, Hakim SG. Defect-related variations in mandibular reconstruction using fibula grafts. A review of 96 cases. $\mathrm{Br}$ J Oral M axillofac Surg 2002;40:322-9. 
8. Daniels S, Ellis 3rd E, Carlson DS. Histologic analysis of costochondral and sternoclavicular grafts in the TMJ of the juvenile monkey. J Oral Maxillofac Surg 1987;45:675-83.

9. Bond SE, Saeed NR, Cussons PD, Watt- Smith SR. Reconstruction of the temporomandibular joint by the transfer of the free vascularised second metatarsal. Brj Oral M axillofac Surg 2004;42:241-5.

10. Zhu SS, Hu J, Li J, Luo E, Liang X, Feng G. Free grafting of autogenous coronoid process for condylar reconstruction in patients with temporomandibular joint ankylosis. Oral Surg Oral Med Oral Pathol Oral Radiol Endod 2008;106:662-7.

11. Loftus MJ, BennettJA, FantasiaJE. Osteochondroma of the mandibular condyles. Report of three cases and review of the literature. Oral Surg Oral Med Oral Pathol 1986;61:221-6.

12. Kent JN, Block MS, Homsy CA, et al: Experience with a polymer glenoid fossa prosthesis for partial or total temporomandibular joint reconstruction.J Oral M axillofac Surg 1986;44:520-533

13. Kent JN, M isiek DJ, Akin RK, et al: Temporomandibular joint condylar prosthesis: A ten year report. J Oral M axillofac Surg 1983;41:245-254

14. Christensen RW: The correction of mandibular ankylosis by arthroplasty and insertion of a cast Vi-tallium glenoid fossa. Journal of the Southern California Dental Association 31:117-118, 1963

15. Christensen RW: The temporomandibular joint prosthesis eleven years later. Oral Implant 2:125-128, 1971.

16. Wolford LM . Temporomandibular joint devices: treatment factors and outcomes.Oral Surg Oral M ed Oral Pathol Oral Radiol Endod 1997: 83:
143-149

17. Louis G. Mercuri, , Larry M. Wolford, ,Bruce Sanders, R. Dean White, Anita Hurder, William Henderson: Custom CAD-CAM Total Temporomandibular Joint Reconstruction System:Preliminary M ulticenter Report. J Oral M axillofac Surg 53:106-115, 1995.

18. L. M. Wolford, M. C. Pitta, O. Reiche-Fischel, P. F. Franco: TM Concepts/Techmedica custom-made TMJ total joint prosthesis: 5year follow-up study. Int. J. Oral M axillofac. Surg. 2003; 32: 268-274.

19. A. Khadka, J. Hu: Autogenous grafts for condylar reconstruction in treatment of TMJ ankylosis: current concepts and considerations for the future. Int. J. Oral M axillofac. Surg. 2012; 41: 94-102.

20. M cCormick SU, Grayson BH, M CCarthy JG, Staffenberg D. Effect of mandibular distraction on the temporomandibular joint: Part 2Clinical study. J Craniofac Surg 1995;6:364-7.

21. Zheng LW, Ma L, Shi XJ, Zwahlen RA, Cheung LK. Comparison of distraction osteogenesis versus costochondral graft in reconstruction of temporomandibular joint condylectomy with disc preservation. J Oral M axillofac Surg 2011;69:409-17.

22. Salgado AJ, Coutinho OP, Reis RL. Bone tissue engineering: state of the art and future trends. M acromol Biosci 2004; 4:743-65.

23. Schek RM, Taboas JM, Hollister SJ, Krebsbach PH. Tissue engineering osteochondral implants for temporomandibular joint repair. Orthod Craniofac Res 2005;8:313-9.

24. Arunachalam Kumar. Temporomandibular joint: the kinetics of elevation and depression. NUJHS2011;1:1-3. 